\title{
Assessment on the Use of Meteorological and Social Media Information for Forest Fire Detection and Prediction in Riau, Indonesia
}

\author{
Anni Arumsari Fitriany ${ }^{1,2, *}$, Piotr J. Flatau ${ }^{3}$, Khoirunurrofik Khoirunurrofik ${ }^{1}\left(\mathbb{C}\right.$ and Nelly Florida Riama ${ }^{2}(\mathbb{C})$ \\ 1 Faculty of Economics and Business, Universitas Indonesia, Depok 16424, Indonesia; khoirunurrofik@ui.ac.id \\ 2 Agency for Meteorology, Climatology, and Geophysics of the Republic of Indonesia, Jakarta 10720, Indonesia; \\ nelly.florida@bmkg.go.id \\ 3 Scripps Institution of Oceanography, University of California San Diego, La Jolla, CA 92093, USA; \\ pflatau@ucsd.edu \\ * Correspondence: anni.arumsari@bmkg.go.id
}

Citation: Fitriany, A.A.; Flatau, P.J.;

Khoirunurrofik, K.; Riama, N.F.

Assessment on the Use of

Meteorological and Social Media Information for Forest Fire Detection and Prediction in Riau, Indonesia. Sustainability 2021, 13, 11188.

https://doi.org/10.3390/su132011188

Academic Editor: Baojie He

Received: 15 August 2021

Accepted: 23 September 2021

Published: 11 October 2021

Publisher's Note: MDPI stays neutral with regard to jurisdictional claims in published maps and institutional affiliations.

Copyright: (c) 2021 by the authors. Licensee MDPI, Basel, Switzerland. This article is an open access article distributed under the terms and conditions of the Creative Commons Attribution (CC BY) license (https:// creativecommons.org/licenses/by/ $4.0 /)$.

\begin{abstract}
In this study, tweets related to fires in Riau, Sumatra, were identified using carefully selected keywords for the 2014-2019 timeframe. The TAGGS algorithm was applied, which allows for geoparsing based on the user's nationality and hometown and on direct referrals to specific locations such as name of province or name of city in the message itself. Online newspapers covering Riau were analyzed for the year 2019 to provide additional information about the reasons why fires occurred and other factors, such as impact on people's health, animal mortality related to ecosystem disruption, visibility, decrease in air quality and limitations in the government firefighting response. Correlation analysis between meteorological information, Twitter activity and satellitederived hotspots was conducted. The existing approaches that BMKG and other Indonesian agencies use to detect fire activity are reviewed and a novel approach for early fire detection is proposed based on the crowdsourcing of tweets. The policy implications of these results suggest that crowdsourced data can be included in the fire management system in Indonesia to support early fire detection and fire disaster mitigation efforts.
\end{abstract}

Keywords: forest fires; meteorology; newspaper; policy; Tweeter; Indonesia

\section{Introduction}

There are large forested areas in Indonesia. Based on 2019 data from the Ministry of Environment and Forestry of the Republic of Indonesia, total forested area covers about 94.1 million hectares, representing almost half of Indonesia's total land-covered area. Though Indonesia benefits from its forestry resources, forest fires also negatively impact aspects of life in Indonesia, in terms of both the economy and health. Tacconi [1] states that the economic cost associated with fires stems not only from the fires themselves, but also from associated smoke and haze, the loss of timber and the loss of opportunity to plant crops. Equally damaging are the costs of firefighting and the loss of property and life. By the same token, the indirect benefits of forested land, such as flood protection and biodiversity, are diminished. Further, smoke impacts health, tourism, transport and industrial production.

Indonesia's land and forest fires are strongly affected by peat soil and land management practices which are often caused by human activities [2], mainly illegal agricultural activities using slash-and-burn techniques to convert forests and peatlands into palm oil plantation fields [3]. This leads to a high frequency of fire activity in such regions, particularly during dry seasons [4]. The fires often produce haze in the peatland areas. There are several types of warnings which can be issued depending on haze severity, such as reduction of outdoor activities or evacuation of the affected areas due to haze-related health issues [5]. According to Ulya et al. [6], forest fires cost public and private companies 
and the government approximately IDR 77.4 million per hectare of burned area. Therefore, urgent policy action in Indonesia requires the improvement of forest fire early detection and warning systems. Rogers and Tsirkunov [7] discuss costs and benefits of such early warning systems. It was shown in one case study in Europe that several hundred lives per year can be saved by employing hydro-meteorological information as part of an early warning system [8]. Prediction and early detection of forest fires are important in order to prevent fires from spreading more intensely. The Indonesian Agency Assessment and Application of Technology (BPPT), in collaboration with the Agency for Meteorology, Climatology, and Geophysics (BMKG), and the Ministry of Environment and Forestry (KLHK) has been operating the Fire Danger Rating System (FDRS) since 1999. Though the FDRS does gauge the probability of fire occurrence, a more direct system would provide valuable information.

This study explores how monitoring large-scale meteorological phenomena, such as El Niño/Southern Oscillation (ENSO) and Indian Ocean Dipole (IOD), as well as data collected from social media, such as Twitter, can contribute to early detection of and thus early warnings of forest fires in Indonesia. We also examine newspaper articles to gain additional information related to "sentiment analysis" related to fires. This will provide guidance and insight for policy makers as they formulate new practices to mitigate forest fires.

This paper consists of a literature review, a detailed discussion of methodology, an analysis of our results and a conclusion section.

\section{Literature Review}

\subsection{Use of Social Media in Early Detection of and Warning of Disaster Events}

Several studies have used information derived from social media and newspapers to study public policy issues, including disaster events. People use Twitter as a way to share their concerns about important societal issues [9]. A study by Biswas [10] shows how news media contribute to the process of policy making by identifying important issues. The use of social media in political communication was studied by Stieglitz and Dang-Xuan [11] who attempted to develop a toolset for collecting, storing, monitoring, analyzing and summarizing user-generated and politically relevant content from social media to be used by political institutions. Sinnenberg [12] has shown how Twitter can be used in health-related studies. Power, et al. [13] state that social media can be a valuable channel of communication. However, its adoption as a source of information to enhance public awareness is still rare [14] because it is not easy to frame social media content in proper context, process large volumes of information nor to trust the messages [15]. Twitter has been used for detecting disasters such as earthquakes [16-18] and floods [19]. Power et al. [20] applied tweets to develop a system for identifying fires in Australia.

Several papers study land and forest fires in Indonesia, including their meteorological and climate indicators [21-23]. Kibanov, et al. [4] reports on social media mining as the source of information related to peatland fires and haze disaster management. Forsyth [24] studied transboundary haze issues in Indonesia, Singapore and Malaysia. Panjaitan, et al. [25] studied forest fire policies in Indonesia, specifically the role of central and local governments and the moderating effects of good governance. Related studies deal with "sentiment analysis". Mustaqim et al. [26] studied public feelings (the "sentiment analysis") about the Indonesian government's response to handling forest fires in 2019 by using a semi-automated labeling and classification scheme. Mustaquim et al. state that sentiment analysis provides a way for businesspeople and academic institutions to better understand community thinking. A recent review of Twitter sentiment analysis can be found in Carvalho and Plastino [27].

\subsection{Indonesian Agencies' Fire-Related Warnings}

The Indonesian government has developed several ways to prevent and mitigate the occurrence of land and forest fires. The KLHK offers a web dashboard for monitoring forest fires called SiPongi. In conjunction with the Geospatial Information Agency, the KLHK provides a forest fire vulnerability map, using physical factors such as land cover, land 
topography, weather and climatology, as well as anthropogenic factors such as human behavior and local socio-culture. The National Disaster Management Agency (BNPB) provides a geospatial dashboard for forest fire mitigation and evacuation. The BMKG provides the Fire Danger Rating System (FDRS), which was developed in collaboration with the Agency for the Assessment and Application of Technology (BPPT) and the Ministry of Environment and Forestry (KLHK). It provides information about the Fine Fuel Moisture Code, Duff Moisture Code, Drought Code, Build Up Index, Initial Spread Index and Fire Weather Index, as well as smoke distribution imagery and hotspot distribution. The Fine Fuel Moisture Code and the Fire Weather Index information are based on weather analysis.

\subsection{Social-Media Based Fire Detection}

In Indonesia, Twitter is used by more than $75 \%$ of all active Internet users. In 2012, Indonesia had the largest global tweet/user ratio in the world [28]. Twitter messages can be merged with weather analysis, an idea which was recently exploited to predict floods in Indonesia [29]. Social media can be an effective communication method, though it remains difficult to analyze a large amount of social media content and determine its appropriateness to fire prediction. Twitter can be used for disaster management during earthquakes [16-18], as many people send messages about such events. Power et al. [20] applied a similar methodology to fire detection; they identified near-real-time tweets that describe fire occurrences and employed a text classifier to refine the results to obtain actual fire occurrences. In a study conducted by Aditya et al. [30], crowdsourcing information was used to validate satellite observations of hotspots and haze. They indicate that their Geocrowd app has the potential to help validate hotspots and to contribute to haze mitigation and environmental protection. They mention that the availability of mobile network signal in remote areas was one of the main obstacles to effective use of the Geocrowd app. They suggested that locally stored reports on the users' mobile devices should be sent when network signal returns.

Power, et al. [23] posits that social media could act as an effective canal of communication. On the other hand, Anderson [14] states that the use of social media has not been widely adopted. There are several difficulties in adopting social media, such as analyzing a large amount of available information and having trust in its content [15]. However, there have been successful studies on the detection of earthquake disasters using social media [16-18].

\subsection{Meteorological Factors}

While some researchers [31-33] mention that the key factor for the occurrence of fires are human activities which clear the land to be used for plantation and agriculture, severe drought conditions induced by the dry phase of climate oscillations can worsen land and forest fires. Several studies indicate that forest fires in Indonesia correlate with dynamical weather conditions and long-term climate indices representing climate oscillations such as El Niño/Southern Oscillation (ENSO) and Indian Ocean Dipole (IOD). In Indonesia, dry conditions are associated with the El Niño phase of ENSO and positive phase of IOD. El Niño events can be classified into two main categories or types based on the location of the maximum sea surface anomaly (SSTA). They are the Eastern Pacific (EP or canonical) El Niño with the maximum SSTA observed in the Eastern Pacific and the Central Pacific (CP or Moldoki) types (Ashok et al. [34]; Yu et al. [35]; Yeh et al. [36]) with the maximum SSTA located in the central Pacific. Studies by Ashok \& Yamagata [37], Yu et al. [35], Yu \& Kim [38], Wang \& Wang [39], and Zhang et al. [40] showed that the different types of El Niño control Walker circulation location and intensity, modifying global circulation and precipitation patterns.

Numerous studies have shown that El Niño events cause intensive fires in Indonesia (C. C. Chen et al. [41]; Fanin \& Werf [42]; Field et al. [43]; Wooster et al. [44]; Yin et al. [45]). A study by Wooster et al. [44] indicates that El Niño, by its influence on precipitation, has a great influence on fire activity magnitude in Kalimantan (Borneo). Their results also 
showed that forecasting El Niño conditions provides ways of estimating the extent and magnitude of fire events several months in advance. Pan et al. [23] recently showed that different types of El Niño can influence the occurrence of Indonesian fires each in a slightly different way; however, both El Niño types are associated with increased droughts and more severe fires (Field et al. [43]). According to Lee and McPhaden [46], in recent years, the El Niño CP type has been appearing more frequently.

Another factor that can modify the Indonesian precipitation pattern, and therefore influence fires, is the Indian Ocean Dipole (IOD). According to Saji et al. [47], IOD develops in the tropical Indian ocean (IO) and is characterized by the reversal of the SST gradient between the eastern and western equatorial Indian ocean. During the positive IOD event, the SST in the western IO is higher than in the eastern IO, modifying the zonal circulation and suppressing precipitation in Indonesia. IOD is usually initiated in a boreal summer, reaches its maximum height in autumn, and quickly falls off in winter. Interactions of the IOD and El Niño create variations in precipitation patterns for the different types of El Niño (Wang \& Wang [39]; Zhang et al. [40]). Earlier studies of fires in Indonesia (Fanin and Werf [42]; Field et al. [43]) showed that the phase of Indian Ocean Dipole (IOD) might modulate fires, particularly when occurring in conjunction with the El Niño phase that also contributes to fires. Recently, Pan et al. [23], using the fire data from 1979 to 2016, showed that taking into consideration the presence of different El Niño and IOD regimes advanced understanding of the role of climate variability in Indonesian fire activity. They classified 12 El Niño events from 1979 to 2016 into Eastern Pacific (EP) and Central Pacific (CP) types (four and eight El Niño events, respectively) and analyzed observational datasets of sea surface temperature, precipitation, drought code, carbon emission associated with biomass burning, optical depth of aerosol and visibility. The results showed that in weather conditions associated with El Niño of the EP type, Indonesian droughts and fires occurred more intensely and were more prolonged, and the carbon amount emitted almost doubled when compared with the weather of the El Niño CP type. However, the IOD effect was evident when the El Niño CP events were further separated according to the phase of IOD. Weakly positive or negative phases of the IOD were associated with less intense burning during the fire season, consistent with increased precipitation during these IOD states.

\section{Materials and Methods}

In order to develop an initial understanding of the feasibility of using social media to augment fire monitoring in Indonesia and to provide supplementary tools for policy makers, we decided to perform a case study to understand the availability of fire-related tweets, newspapers reports and weather-related large-scale factors and their correlation with satellite-derived products. To this end, we focused our study on the Riau Province of Sumatra Island, Indonesia.

We choose Riau Province because it is situated in one of the most vulnerable locations in Indonesia for the occurrence of land and forest fires. Its location, which is close to neighboring countries such as Singapore and Malaysia, means that fires and associated smoke create a problem both in Indonesia itself as well as causing transboundary haze transport to the afore-mentioned countries.

Hotspot data from the MODIS satellite sensor on Terra and Aqua satellites from 2015 to 2019 is used to examine occurrences of forest fires in the Riau area. The ENSO and IOD events are identified using their respective indices. Newspaper data related to forest fires in Riau from 1 January 2019 to 31 December 2019 were examined, as well as five years of Twitter data from 2015 to 2019. This is described in more detail below.

\subsection{Satellite Data Collection, Construction and Analysis}

The satellite hotspot data from the MODIS satellite sensor on Terra and Aqua satellites and SNPP satellite were used to define the occurrences of land and forest fires from 2015 to 2019. The data was collected from a LAPAN site [16]. The MODIS (Moderate-Resolution Imaging Spectroradiometer) both on Terra and Aqua are based on channels 21 and 22 
(3.92-3.98 $\mu \mathrm{m}$ ) with spatial resolution of $1 \mathrm{~km}$. The S-NPP (Suomi National Polar Orbiting Partnership) satellite data is based on the VIIRS sensor and uses channel 14 between 3.55 and $3.93 \mu \mathrm{m}$ with spatial resolution of $375 \mathrm{~m}$. These satellites observe Indonesia twice daily on their polar orbit. The LAPAN system allows for retrieval of data for a specific province or latitude and longitude box. One can also define a specific time period, confidence level and satellite observing system. The data is in the form of CSV files with latitude, longitude, relative humidity (\%), name of satellite system (Aqua, Terra, SNPP) and date. Discussion of satellite data analysis is beyond the scope of this study, but in short, satellite inversion techniques retrieve the surface temperature by observing incoming radiance in the near-infrared spectrum region.

\subsection{Meteorological Data Collection, Construction and Analysis}

The ENSO and IOD indices data were used to identify El Niño and positive IOD events and confirm whether there is a connection between meteorological conditions and forest fires in Indonesia. Data for a 2015-2019 period were used. The Niño 3.4 index data and Dipole Mode Index (DMI) were used to identify ENSO and IOD phases, respectively. Both datasets are obtained from the Climate Prediction Center (CPC) of the National Weather Services, National Oceanic and Atmospheric Administration (NOAA). According to the CPC climate guide, the Niño 3.4 index reflects the SST anomaly averaged for the (5 N-5 S, $170 \mathrm{~W}-120 \mathrm{~W}$ ) region. The Niño 3.4 index typically uses a 5-month running mean, and El Niño or La Niña events are defined as conditions when the Niño 3.4 SSTs exceed + / - 0.4 C for a period of six months or more. The meteorological data sets are quality controlled by the Climate Prediction Center (CPC) of the National Weather Services. No further quality control of the data was performed. DMI is defined as a difference between the SSTA in the western (10 S-10 N, 50 E-70 E) and eastern (10 S-0 N, 90 E-110 E) Indian Ocean.

\subsection{Newspaper Data Collection, Construction and Analysis}

The data was collected by searching fire-related keywords and reading online newspaper articles. We tried to estimate the duration, location, latitude and longitude (based on city mentioned in an article). We also collected the URL of the online newspaper and its name. We used Antara News for the Riau region and other online accessible sources of information. A qualitative content analysis related to fires from newspapers was conducted. Information from online newspapers was collected from the 1 January 2019 to 31 December 2019. The newspaper analysis also gave us information about the reason why fires occurred and other information such as impact on people's health, animal mortality related to ecosystem disruption, visibility and decrease in air quality, as well as limitations related to the government firefighting response. The purpose of newspaper analysis was not quantitative but was necessary to better understand issues related to policy making which would have been otherwise difficult to grasp just from numerical information about the number of hotspots and the number of tweets.

\subsection{Twitter Data Collection, Construction and Analysis}

Twitter messages form a mini blog, with a single tweet containing no more than 280 characters. Such messages were also used to confirm whether there is a connection between Twitter and the land and forest fire events from 2015-2019 in Riau, Indonesia. The limitation of the number of characters used on Twitter forces messages to be short and precise. Twitter messages provide some metadata with every tweet which may include location of tweet, author's name and the time when the tweet was posted. However, gathering and analyzing Twitter messages may be challenging because of data access and metadata uncertainties. There are several ways of obtaining historical tweets. For example, one can use Twitter API; however, for standard users there is only access to the previous 7 days. There are also some paid datasets, such as GNIP. There are some Twitter datasets available, but none addressing fires in Indonesia. Therefore, we used scrapping script to obtain the Twitter data. 
Using the GetOldTweets-python, we were able to search twitter for the 5-year period between 2015 and 2019 for all of Indonesia using (separately) the following keywords: forest fire: kebakaran hutan, land fire: kebakaran lahan, smoke: asap, no rain: tidak ada hujan, fire: api, drought: kekeringan.

In the 5-year period, we located about 1,250,000 tweets which satisfied our search criteria. In contrast, only 50,000 of them contained the keyword "kekeringan" (draught). For fire events, we did not include "no-rain" and "drought" keywords; these were used to understand the number of tweets related to drought. The "smoke" keyword was used separately to understand possible "smoke" hazard related to fire events. Therefore, "fire" keywords dominated by far the total amount of retrieved tweets.

To analyze tweets, we needed to know date and place as well as number of relevant tweets. Dates are provided with individual tweets. Determining location is the most difficult task. Due to privacy concerns, tweets do not include GPS latitude and longitude position (even though users can provide such data) which would have been the simplest way of obtaining location. Unfortunately, less than $1 \%$ of all tweets contain such information. This significantly lowers the number of tweets available for analysis. To overcome this limitation, one can analyze tweet text and its metadata to provide an estimated event location. The geoparsing algorithm TAGGS of de Bruijn [19] was used to determine geographical locations. The TAGGS algorithm allows geoparsing based on the user's nationality (for example Bahasa language) and their hometown. One can also discover direct referrals to specific locations. For example, it can be the name of the province or the name of a city in the message itself. Such an estimation method may result in a certain number of messages being assigned to an inaccurate location, but since we rely on a large number of tweets to identify fire events, we obtained a large signal that minimizes noise from potentially inaccurate geoparsing location.

\section{Results and Discussion}

\subsection{The Analysis of Meteorological and Climatological Conditions and Drought Effects}

The Niño 3.4 and the indices of the IOD from the NOAA's CPC in the 2015-2019 timeframe are shown in Figure 1. We can see that positive Niño 3.4 and IOD occurred in April-December 2015, March-July 2017, July-December 2018 and May-December 2019, thus providing insights into climatological forcings in Indonesia for that period. It appears that the conditions preferable for increase in Indonesian fires were observed in 2015/2016 (El Niño) and 2019 (El Niño and positive IOD).

(a) Niño 3.4

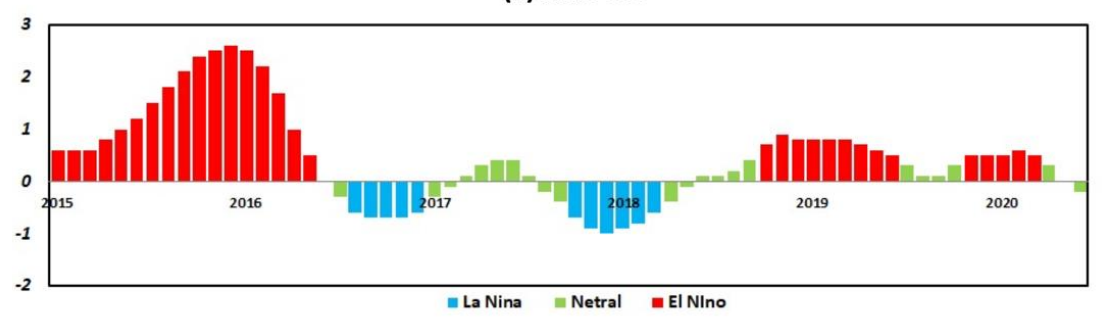

(b) DMI (IOD)

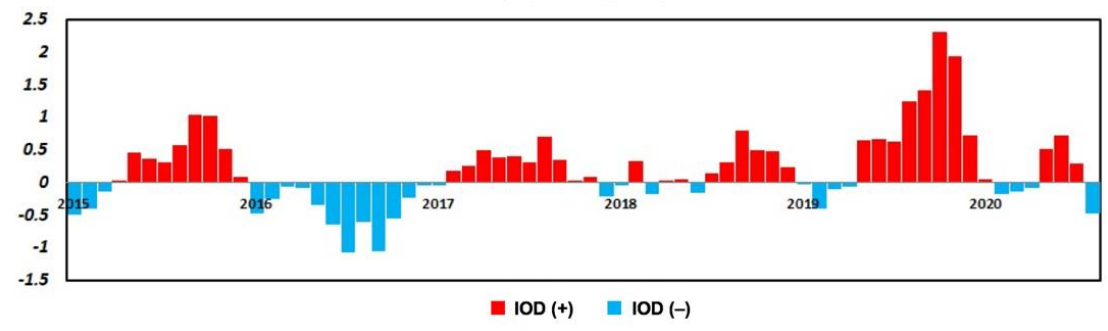

Figure 1. The Niño 3.4 and DMI (IOD) indices during periods of drought for 2015 to 2019. 


\subsection{The Analysis of the Newspaper Data}

We analyzed the content of 31 articles on 2019 fire events as reported in the online Riau Antara Newspaper (https:/ / riau.antaranews.com, accessed in 10 January 2020). From these articles one can deduce that the 2019 forest fires season started on 31 December 2018. The fires were mostly burning peatlands with some areas covered by shrub vegetation, palm oil trees and rubber plantation vegetation. In early 2019, some newspapers reported that forest fires occurred due to the dry season without rainfall and with strong winds and from land clearing for plantations and grass burning by people.

On 11 January 2019, newspapers reported that the burning area had reached up to 267.5 hectares and that local disaster management in Riau considered themselves on "standby" (ready for action) status related to forest and land fires in Riau, but to issue a final decision, they needed to coordinate with various institutions such as the Indonesian Agency for Meteorology, Climatology, and Geophysics (BMKG) and the Riau Provincial Government. Subsequently, on 18 February 2019, "standby" status related to land and forest fires had been declared for Bengkalis Regency and Dumai City but it was not yet determined at the level of the entire Riau province. It was also mentioned that "standby" status could be issued at the provincial level if two or more regencies or cities determined that such status was warranted. It took more than a month for "standby" status for forest and land fires in the Province of Riau to be declared. By that time, approximately 842 hectares in Riau had burned. It was also written that once the Riau Provincial Government determined "standby" status regarding land and forest fires, they could immediately coordinate with the National Disaster Management Agency (BNPB) for support and assistance, such as asking for additional information, requesting helicopters or other resources.

Some newspapers also reported difficulties in the field during efforts to extinguish fires. Locations were sometimes difficult to reach because of difficult terrain, no access to roads, the necessity of using small boats through mangrove forests or access by foot only. On occasion, winds were so strong that fires spread too quickly for people to react.

In summary, newspapers do provide insight into problems that occur in the field during firefighting and show how the government responds while dealing with many regulations-the result being that this bottom-up approach creates a delayed response. However, using newspapers has the constraint of a lack of information on the exact location of fires. Further, newspaper information is often delayed, and fire start times are not provided.

\subsection{Analysis of Twitter Data}

Twitter data on land and forest fires in Riau from 2015 to 2019 was compared with the occurrences of fires from MODIS satellite images for the same period (Figure 2). These plots, comparing the number of tweets and the number of hotspots, show consistency between them. For example, when the number of hotspots in 2015, 2016 and 2019 is large, the number of tweets is also high.

\subsection{Empirical Analysis of Social Media Response}

Hotspots vs. tweet scatterplots for 2015-2019 (Figure 3) show correlation of about 0.04 in 2015, 0.22 in 2016, 0.001 in 2017, 0.12 in 2018, and 0.089 in 2019, and the correlation between hotspot and Twitter data (not shown) for the whole year ranges from 0.04 to 0.39 . This may be because of insufficient data in some months where there are no tweets or hotspots. However, for the dry season between August to October when drought conditions occur in Riau, there is better correlation, between 0.21 and 0.47 (Table 1). When hotspot occurrences are high as in 2015 and 2019, the correlation is lower compared to years when the hotspot occurrences are smaller. This may indicate that people are more concerned with fires during the dry season. 

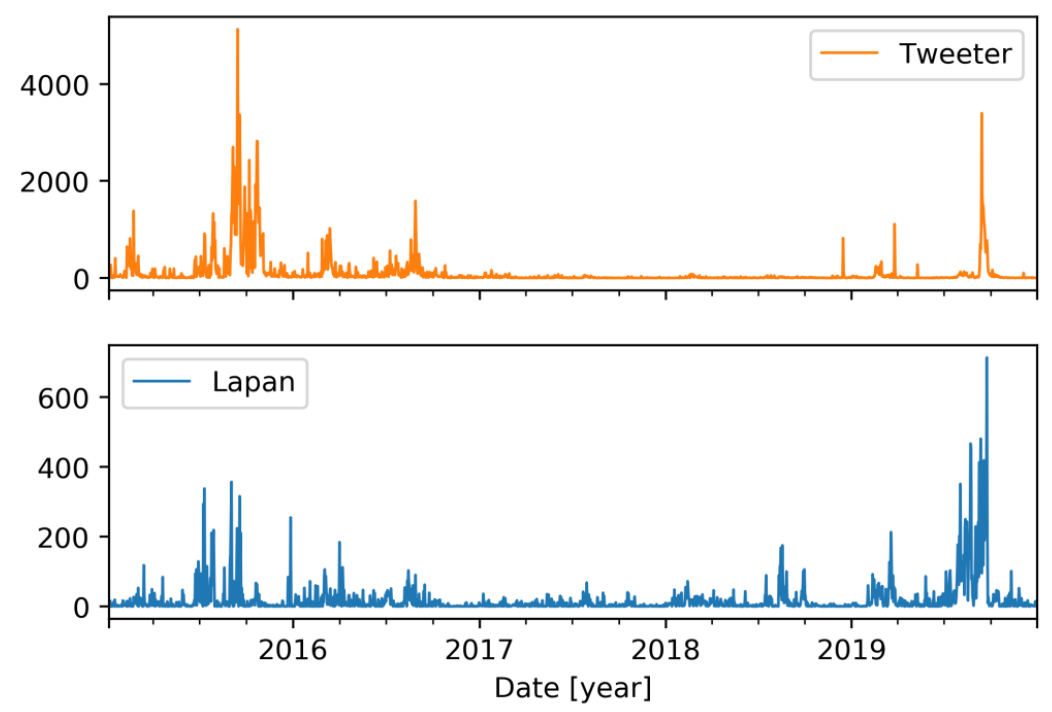

Figure 2. Number of tweets and hotspot occurrence from MODIS satellite images in Riau, 2015-2019.

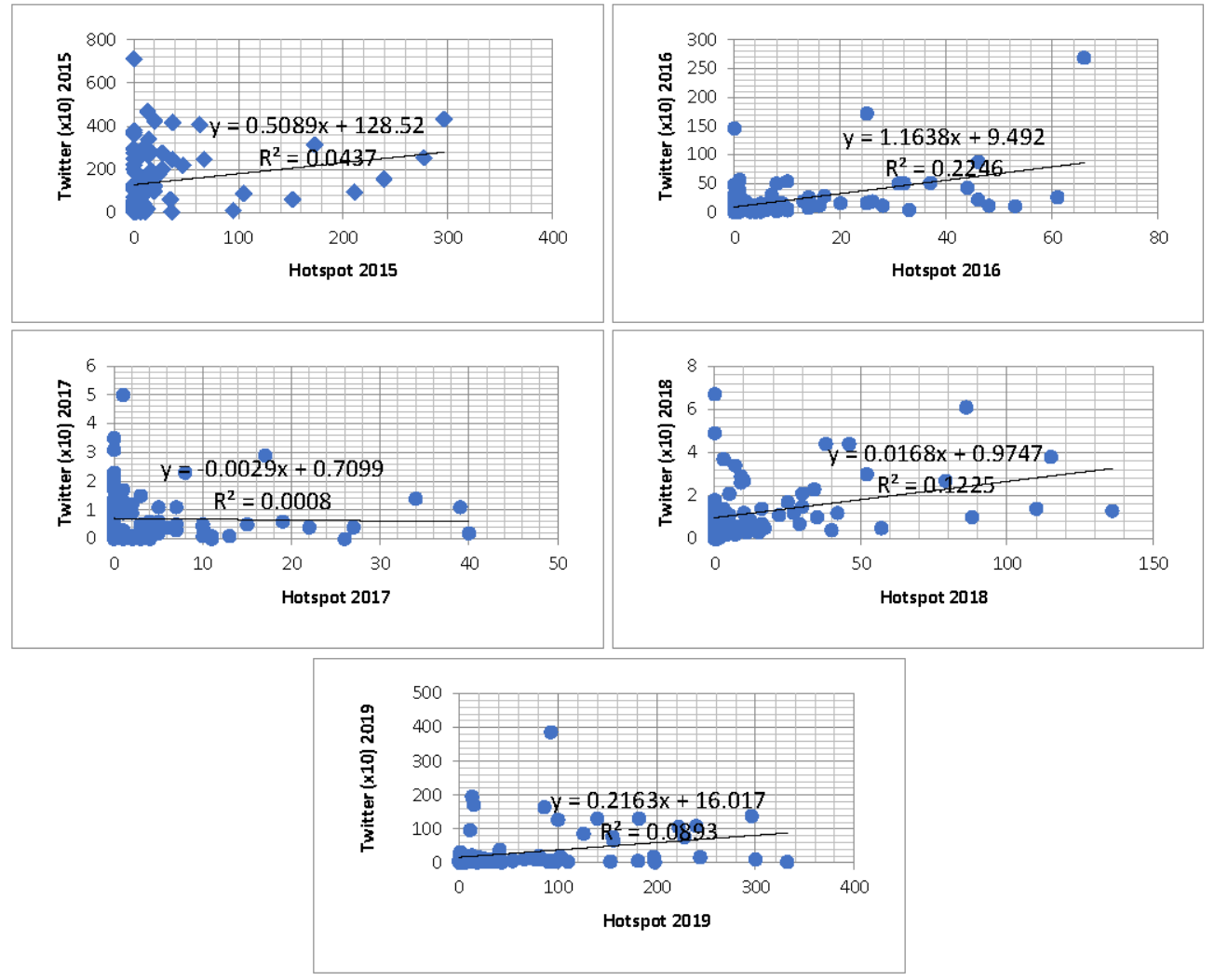

Figure 3. Annual trend of the scatterplot between hotspots and tweets from 2015 to 2019.

We grouped tweets and hotspots into monthly groups and calculated correlation between them for all the years. During 2015, 2016 and 2019, such correlation is high: $0.71,0.85$ and 0.84 respectively (Table 2 and Figure 4). Therefore, when monthly hotspot occurrences are high, such as in 2015, 2016 and 2019, the correlation is also high comparing to years when the hotspot occurrences are smaller and this monthly correlation for each year is also reflected in the total burnt data for each year. 
Table 1. Yearly correlation between the number of hotspots and the number of tweets in Riau from 2015 to 2019.

\begin{tabular}{ccc}
\hline Year & $\begin{array}{c}\text { Tweet-Hotspot } \\
\text { Correlation } \\
\text { (January-December) }\end{array}$ & $\begin{array}{c}\text { Tweet-Hotspot } \\
\text { Correlation } \\
\text { (August-October) }\end{array}$ \\
\hline 2015 & 0.2714 & 0.2091 \\
2016 & 0.3847 & 0.4739 \\
2017 & 0.0535 & 0.2091 \\
2018 & 0.0421 & 0.4739 \\
2019 & 0.3873 & 0.2060 \\
\hline
\end{tabular}

Source: Authors' calculation.

Table 2. Hotspot-Twitter (monthly total) correlation and total burnt area in Riau, 2015-2019.

\begin{tabular}{ccc}
\hline Year & $\begin{array}{c}\text { Monthly Hotspot-Monthly } \\
\text { Twitter Correlation }\end{array}$ & $\begin{array}{c}\text { Total Burnt Area } \\
\text { (in 100,000) }\end{array}$ \\
\hline 2015 & 0.7094 & 1.8381 \\
2016 & 0.8567 & 0.8522 \\
2017 & 0.3330 & 0.0687 \\
2018 & 0.1094 & 0.3724 \\
2019 & 0.8435 & 0.9055 \\
\hline
\end{tabular}

Source: Authors' calculation.

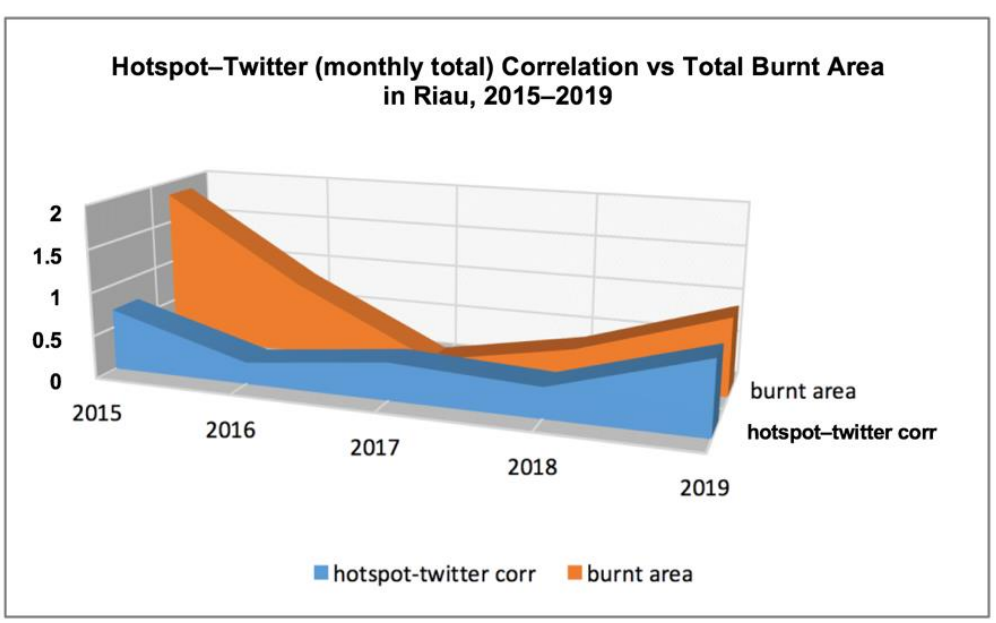

Figure 4. Total hotspotTwitter correlation and total burnt area in Riau, 2015-2019.

Social media information from newspapers and Twitter data provide important information that can support land and forest fire management decisions. For example, one can derive such information as fire location, time of fire occurrence, impact and risk faced by the community, health issues related to smoke, causes of fires and problems experienced in the field by firefighters.

The content analysis of the newspapers show that the requirements needed to establish "standby status" for land and forest fires at the provincial level, which results in support from the central government, are often too onerous. This leads to worsening conditions, causing the fire to spread and become more difficult to contain. The bottom-up approach would be fine for normal weather and climate conditions. However, a top-down approach is strongly required during extreme conditions of weather and climate.

The Twitter analysis shows that total monthly tweets and total monthly hotspots are well correlated, and this provides beneficial information for usage of Twitter data. Newspapers and Twitter information associated with forest fires show that they can provide additional near-real-time information on forest fire detection that is beneficial for forest fire management policy makers in deciding on approaches to fire prevention and mitigation. 
Number of tweets, as it changes, might serve as an alert for decision makers to consider in order to determine appropriate steps to address problems on the ground.

Clearly there is no 1:1 correspondence between Twitter data and satellite hotspots. There can be several reasons for this: (1) Tweets can be sent before satellite hotspots are observed, particularly when fires are just starting, and satellite detection algorithms are not sensitive enough. On the other hand, satellites observe remote areas where mobile networks needed for tweeting do not have enough coverage, or where there are few people. In this case, hotspots will be recorded before tweets appear. (2) Another reason is the tweet "memory" effect in which tweets grow over time and "explode" when the intensity of the event is large. There may be also a long decay of tweets after a particularly intense fire event. In other words, tweets are a "social phenomenon". People discuss the event and tweet about subsequent health issues and displacement. This is why we observe long "Twitter memory". (3) There also may be a discrepancy because some events lead to tweets which are not from the locality where the fire occurred. For example, relatives in Jakarta may tweet about particularly large fires in Riau.

More research such as artificial intelligence Natural Language Processing (NLP) could be used to analyze fire-related Twitter messages and their discrepancies with hotspot data. For example, in the context of Twitter and floods, de Bruijin et al. [48] adopted the cased multilingual version of BERT to categorize tweets into two groups: the group which is associated with the ongoing event ("relevant") and the group which is not associated with the ongoing event ("irrelevant"). BERT processes the correlations between the words and sub-words in a text using the Natural Language Processing (NLP) model which is based on deep learning. However, such an analysis is beyond the scope of the current work. One intriguing angle would be the development of semi-automatic sentiment analysis as suggested recently by Mustaqim et al. [26], but one which would also provide satellite and meteorological data.

Even though tweets are "social media", our research illustrates how objectively derived information from hotspots correlate with tweets, thus providing a glimpse of how they can be used in future events for better policy making. For example, large events are well captured by a strong, sharp rise in tweet volume. We also observed a "memory effect" in which tweets are more "sentiment"-related, but these may nevertheless be useful for policy makers because even after the fires were extinguished, they were still being discussed in villages and cities.

\section{Conclusions}

We follow here the methodology of Saura, et al. [49] and Ribeiro-Navarrete, et al. [50] while summarizing the results. Social media information about fires, combined with data on forest and land fires, such as satellite-derived hotspots, wind velocity and speed, and rainfall and moisture content provide an additional source of information which can be used for near-real time forecasting and policy decision making. Newspapers do provide insight into problems that occur in the field during firefighting and how the government responds while faced with a complex regulatory framework. This often results in a bottomup approach which can create delayed action. We also discuss that large-scale weather and oceanic state indices such as Indian Ocean Dipole and El Niño are well correlated with forest fire occurrences, thereby providing an additional estimation variable for forest fire detection. This work is relevant to the Riau province land and forest fires which are linked to the presence of peat soil and certain land management practices. We note that such practices lead to this region's high frequency of fire activity mostly during the dry seasons. It is observed that the remoteness of these areas is a factor in attempting to develop alternative detection tools for warning, such as tracking of Twitter messages. The government of Indonesia has tried many approaches to prevent and mitigate the occurrence of forest and land fires in Indonesia. In this study, existing approaches taken by the BMKG and other Indonesian agencies to estimate fire activity are reviewed and a novel approach based on crowdsourcing of Twitter messages is proposed. 


\subsection{Managerial Implication}

Our results suggest the following: (1) A top-down approach is required for the extreme weather and climate conditions related to land and forest fires. (2) Since the dynamic condition of weather and climate phenomena is strongly correlated to fire intensity in Indonesia, the government needs to include these factors in its Fire Rating Danger System and forest fires vulnerability maps through the identification of the El Niño type and phase of IOD. In the future, even shorter time scale events such as Convectively Coupled Equatorial Waves and Madden-Julian Oscillations should be included. (3) Newspaper and Twitter data could also be included in the fire management system to support early detection of and timely warnings about fires.

\subsection{Practical/Social Implications}

Our findings provide some alternative ways for policy makers within the Indonesian government to prevent and mitigate the occurrence of land and forest fires.

\subsection{Limitations and Future Research}

This study can be extended in several ways. The development of a land and forest fire disaster threats index could be enhanced by adding information about weather and climate conditions. Of particular importance would be the forecasting of short term weather events such as Convectively Coupled Kelvin Waves and tropical disturbances such as Mesoscale Convective Systems and information about sudden onsets of droughts [51] which may contribute to sudden fire onsets. Incentives to provide Twitter information could be developed; enhanced mobile signal networking capabilities in remote areas would increase the viability of our proposed approach. "Public sentiment" analysis can be performed as to how people feel about government response and actions as concerns land and forest fire mitigation. We addressed this issue only in a cursory way in this study, but such sentiment analysis can be used to extend the methodology developed here.

Author Contributions: Conceptualization, A.A.F. and P.J.F.; methodology, A.A.F., P.J.F. and K.K.; software, P.J.F.; validation, A.A.F. and P.J.F.; investigation, A.A.F.; writing-original draft preparation, A.A.F.; writing-review and editing, A.A.F., P.J.F., K.K. and N.F.R.; visualization, A.A.F. and P.J.F.; supervision, K.K.; project administration, K.K. and N.F.R. All authors have read and agreed to the published version of the manuscript.

Funding: P.J.F. has been supported in part by NSF grant 1724741 “Equatorial Line Observations (ELO) field campaign during the International Years of Maritime Continent" program managed by Eric T. DeWeaver. The Agency for Meteorology, Climatology, and Geophysics of the Republic of Indonesia (BMKG) contribution supported the Years of Maritime Continent ELO project.

Institutional Review Board Statement: Not applicable.

Informed Consent Statement: Not applicable.

Data Availability Statement: The satellite related to this paper can be downloaded from LAPAN site http:/ / modis-catalog.lapan.go.id/monitoring/ (accessed 24 September 2021). El Niño and Indian Ocean Dipole (IOD) Indices are available from https: / / psl.noaa.gov/gcos_wgsp/Timeseries/DMI/ (accessed 24 September 2021). All the newspaper data were collected by searching online open newspaper sources. The tweet datasets analyzed and generated during the current study are not publicly available due to Twitter's privacy policy but are available from the corresponding author upon a reasonable request in line with the policy. The TAGGS code is publicly available on GitHub ( https:/ /github.com/jensdebruijn/TAGGS, accessed 23 September 2021). The Twittercode can be found on the github site: https:/ / github.com/Jefferson-Henrique/GetOldTweets-python, accessed 23 September 2021.

Acknowledgments: The satellite hotspot data from MODIS satellite sensor on Terra and Aqua satellites and SNPP were obtained from LAPAN MODIS monitoring site. The Niño 3,4 index data were taken from the Climate Prediction Center (CPC) of the National Weather Services, National Oceanic and Atmospheric Administration (NOAA). The authors acknowledge the help of Maria Flatau with discussion of large-scale indices. Michał Łabuz processed the TAGGS algorithm and 
collected Twitter data. Katarzyna Barabasz and Beata Latos helped with analysis of newspaper data, and Dawid Gacek helped with data plotting. Tracy Stevens and Dariusz Baranowski helped to improve the manuscript.

Conflicts of Interest: The authors declare no conflict of interest.

\section{References}

1. Tacconi, L. Fires in Indonesia: Causes. Cost Policy Implic. Bogor CIFOR 2003. [CrossRef]

2. Kim, D.; Sexton, J.O.; Townshend, J.R. Accelerated deforestation in the humid tropics from the 1990s to the 2000s. Geophys. Res. Lett. 2015, 42, 3495-3501. [CrossRef]

3. Holmgren, P. Fire and haze in Riau: Looking beyond the hotspots. Cent. Int. For. Res. Bogor Indones. 2013. Available online: https://www2.cifor.org/forestsasia/fire-haze-riau-looking-beyond-hotspots/index.html (accessed on 10 January 2020).

4. Kibanov, M.; Stumme, G.; Amin, I.; Lee, J.G. Mining social media to inform peatland fire and haze disaster management. Soc. Netw. Anal. Min. 2017, 7, 1-19. [CrossRef]

5. Frankenberg, E.; McKee, D.; Thomas, D. Health consequences of forest fires in Indonesia. Demography 2005, 42, 109-129. [CrossRef]

6. Ulya, N.A.; Yunardy, S. Analisis dampak kebakaran hutan di Indonesia terhadap distribusi pendapatan masyarakat. J. Penelit. Sos. Dan Ekon. Kehutan. 2006, 3, 133-146. [CrossRef]

7. Rogers, D.; Tsirkunov, V. Costs and benefits of early warning systems. Global Assessment Report, 1 January 2011.

8. Hallegatte, S. A cost effective solution to reduce disaster losses in developing countries: Hydro-meteorological services, early warning, and evacuation. World Bank Policy Res. Work. Pap. 2012. Available online: https://openknowledge.worldbank.org/ handle/10986/9359 (accessed on 10 January 2020).

9. Kalogeropoulos, A.; Negredo, S.; Picone, I.; Nielsen, R.K. Who shares and comments on news?: A cross-national comparative analysis of online and social media participation. Soc. Media Soc. 2017, 3, 2056305117735754. [CrossRef]

10. Biswas, M. An exploratory research: A comparative analysis of mainstream and ethnic media coverage of social policy issues in the economic stimulus plan debate. J. Comp. Soc. Welf. 2010, 26, 13-26. [CrossRef]

11. Stieglitz, S.; Dang-Xuan, L. Social media and political communication: A social media analytics framework. Soc. Netw. Anal. Min. 2013, 3, 1277-1291. [CrossRef]

12. Sinnenberg, L.; Buttenheim, A.M.; Padrez, K.; Mancheno, C.; Ungar, L.; Merchant, R.M. Twitter as a tool for health research: A systematic review. Am. J. Public Health 2017, 107, e1-e8. [CrossRef]

13. Power, R.; Robinson, B.; Colton, J.; Cameron, M.A. A Case Study for Monitoring Fires with Twitter. In Proceedings of the ISCRAM, Kristiansand, Norway, 24-27 May 2015.

14. Anderson, M. Integrating social media into traditional emergency management command and control structures: The square peg into the round hole. In Proceedings of the Disaster and Emergency Management Conference Proceedings, Brisbane, Australia, 16-18 April 2012; pp. 18-34.

15. Lindsay, B.R. Social Media and Disasters: Current Uses, Future Options, and Policy Considerations; UNT Library: Denton, TX, USA, 2011.

16. Sakaki, T.; Okazaki, M.; Matsuo, Y. Tweet analysis for real-time event detection and earthquake reporting system development. IEEE Trans. Knowl. Data Eng. 2012, 25, 919-931. [CrossRef]

17. Robinson, B.; Power, R.; Cameron, M. A sensitive twitter earthquake detector. In Proceedings of the 22nd International Conference on World Wide Web, Rio de Janeiro, Brazil, 13-17 May 2013; pp. 999-1002.

18. Avvenuti, M.; Cresci, S.; Marchetti, A.; Meletti, C.; Tesconi, M. Ears (earthquake alert and report system) a real time decision support system for earthquake crisis management. In Proceedings of the 20th ACM SIGKDD International Conference on Knowledge Discovery and Data Mining, New York, NY, USA, 24-27 August 2014; pp. 1749-1758.

19. de Bruijn, J.A.; de Moel, H.; Jongman, B.; Wagemaker, J.; Aerts, J.C. TAGGS: Grouping tweets to improve global geoparsing for disaster response. J. Geovisualization Spat. Anal. 2018, 2, 2. [CrossRef]

20. Power, R.; Robinson, B.; Ratcliffe, D. Finding fires with twitter. In Proceedings of the Australasian Language Technology Association Workshop 2013 (ALTA 2013), Brisbane, Australia, 4-6 December 2013; pp. 80-89.

21. Reid, J.; Xian, P.; Hyer, E.; Flatau, M.; Ramirez, E.; Turk, F.; Sampson, C.; Zhang, C.; Fukada, E.; Maloney, E. Multi-scale meteorological conceptual analysis of observed active fire hotspot activity and smoke optical depth in the Maritime Continent. Atmos. Chem. Phys. 2012, 12, 2117-2147. [CrossRef]

22. Shawki, D.; Field, R.D.; Tippett, M.K.; Saharjo, B.H.; Albar, I.; Atmoko, D.; Voulgarakis, A. Long-lead prediction of the 2015 fire and haze episode in Indonesia. Geophys. Res. Lett. 2017, 44, 9996-10005. [CrossRef]

23. Pan, X.; Chin, M.; Ichoku, C.M.; Field, R.D. Connecting Indonesian fires and drought with the type of El Niño and phase of the Indian Ocean dipole during 1979-2016. J. Geophys. Res. Atmos. 2018, 123, 7974-7988. [CrossRef]

24. Forsyth, T. Public concerns about transboundary haze: A comparison of Indonesia, Singapore, and Malaysia. Glob. Environ. Chang. 2014, 25, 76-86. [CrossRef]

25. Panjaitan, R.B.; Sumartono, S.; Sarwono, S.; Saleh, C. The role of central government and local government and the moderating effect of good governance on forest fire policy in Indonesia. Benchmarking Int. J. 2019, 26, 147-159. [CrossRef]

26. Mustaqim, T.; Umam, K.; Muslim, M. Twitter Text Mining for Sentiment Analysis on Government's Response to Forest Fires with Vader Lexicon Polarity Detection and K-Nearest Neighbor Algorithm; IOP Publishing: Bristol, UK, 2020; Volume 1567, p. 032024. 
27. Carvalho, J.; Plastino, A. On the evaluation and combination of state-of-the-art features in Twitter sentiment analysis. Artif. Intell. Rev. 2021, 54, 1887-1936. [CrossRef]

28. Carley, K.M.; Malik, M.M.; Kowalchuck, M.; Pfeffer, J.; Landwehr, P. Twitter Usage in Indonesia 2015. Available online: https: / / ssrn.com/abstract=2720332 (accessed on 23 September 2021).

29. Baranowski, D.B.; Flatau, M.K.; Flatau, P.J.; Karnawati, D.; Barabasz, K.; Labuz, M.; Latos, B.; Schmidt, J.M.; Paski, J.A. Socialmedia and newspaper reports reveal large-scale meteorological drivers of floods on Sumatra. Nat. Commun. 2020, 11, 1-10. [CrossRef] [PubMed]

30. Aditya, T.; Laksono, D.; Izzahuddin, N. Crowdsourced hotspot validation and data visualisation for location-based haze mitigation. J. Locat. Based Serv. 2019, 13, 239-269. [CrossRef]

31. Goldammer, J.G. History of equatorial vegetation fires and fire research in Southeast Asia before the 1997-98 episode: A reconstruction of creeping environmental changes. Mitig. Adapt. Strateg. Glob. Chang. 2007, 12, 13-32. [CrossRef]

32. Goldammer, J.G.; Seibert, B. The impact of droughts and forest fires on tropical lowland rain forest of East Kalimantan. In Fire in the Tropical Biota; Springer: Berlin/Heidelberg, Germany, 1990; pp. 11-31.

33. Simorangkir, D. Fire use: Is it really the cheaper land preparation method for large-scale plantations? Mitig. Adapt. Strateg. Glob. Chang. 2007, 12, 147-164. [CrossRef]

34. Ashok, K.; Behera, S.K.; Rao, S.A.; Weng, H.; Yamagata, T. El Niño Modoki and its possible teleconnection. J. Geophys. Res. Oceans 2007, 112. [CrossRef]

35. Yu, J.-Y.; Kao, H.-Y.; Lee, T.; Kim, S.T. Subsurface ocean temperature indices for Central-Pacific and Eastern-Pacific types of El Niño and La Niña events. Theor. Appl. Climatol. 2011, 103, 337-344. [CrossRef]

36. Yeh, S.-W.; Kug, J.-S.; Dewitte, B.; Kwon, M.-H.; Kirtman, B.P.; Jin, F.-F. El Niño in a changing climate. Nature 2009, 461, 511-514. [CrossRef]

37. Ashok, K.; Yamagata, T. The El Niño with a difference. Nature 2009, 461, 481-484. [CrossRef] [PubMed]

38. Yu, J.; Kim, S.T. Identifying the types of major El Niño events since 1870. Int. J. Climatol. 2013, 33, 2105-2112. [CrossRef]

39. Wang, X.; Wang, C. Different impacts of various El Niño events on the Indian Ocean Dipole. Clim. Dyn. 2014, 42, 991-1005. [CrossRef]

40. Zhang, W.; Wang, Y.; Jin, F.; Stuecker, M.F.; Turner, A.G. Impact of different El Niño types on the El Niño/IOD relationship. Geophys. Res. Lett. 2015, 42, 8570-8576. [CrossRef]

41. Chen, Y.; Morton, D.C.; Andela, N.; Van Der Werf, G.R.; Giglio, L.; Randerson, J.T. A pan-tropical cascade of fire driven by El Niño/Southern Oscillation. Nat. Clim. Chang. 2017, 7, 906-911. [CrossRef]

42. Fanin, T.; Werf, G.R. Precipitation-fire linkages in Indonesia (1997-2015). Biogeosciences 2017, 14, 3995-4008. [CrossRef]

43. Field, R.D.; Van Der Werf, G.R.; Fanin, T.; Fetzer, E.J.; Fuller, R.; Jethva, H.; Levy, R.; Livesey, N.J.; Luo, M.; Torres, O. Indonesian fire activity and smoke pollution in 2015 show persistent nonlinear sensitivity to El Niño-induced drought. Proc. Natl. Acad. Sci. USA 2016, 113, 9204-9209. [CrossRef] [PubMed]

44. Wooster, M.; Perry, G.; Zoumas, A. Fire, drought and El Niño relationships on Borneo (Southeast Asia) in the pre-MODIS era (1980-2000). Biogeosciences 2012, 9, 317-340. [CrossRef]

45. Yin, Y.; Ciais, P.; Chevallier, F.; Van der Werf, G.R.; Fanin, T.; Broquet, G.; Boesch, H.; Cozic, A.; Hauglustaine, D.; Szopa, S. Variability of fire carbon emissions in equatorial Asia and its nonlinear sensitivity to El Niño. Geophys. Res. Lett. 2016, 43, 10-472. [CrossRef]

46. Lee, T.; McPhaden, M.J. Increasing intensity of El Niño in the central-equatorial Pacific. Geophys. Res. Lett. 2010, 37. [CrossRef]

47. Saji, N.; Goswami, B.N.; Vinayachandran, P.; Yamagata, T. A dipole mode in the tropical Indian Ocean. Nature 1999, 401, 360-363. [CrossRef]

48. de Bruijn, J.A.; de Moel, H.; Jongman, B.; de Ruiter, M.C.; Wagemaker, J.; Aerts, J.C. A global database of historic and real-time flood events based on social media. Sci. Data 2019, 6, 1-12. [CrossRef]

49. Saura, J.R.; Palacios-Marqués, D.; Iturricha-Fernández, A. Ethical design in social media: Assessing the main performance measurements of user online behavior modification. J. Bus. Res. 2021, 129, 271-281. [CrossRef]

50. Ribeiro-Navarrete, S.; Saura, J.R.; Palacios-Marqués, D. Towards a new era of mass data collection: Assessing pandemic surveillance technologies to preserve user privacy. Technol. Forecast. Soc. Chang. 2021, 167, 120681. [CrossRef]

51. Pendergrass, A.G.; Meehl, G.A.; Pulwarty, R.; Hobbins, M.; Hoell, A.; AghaKouchak, A.; Bonfils, C.J.; Gallant, A.J.; Hoerling, M.; Hoffmann, D. Flash droughts present a new challenge for subseasonal-to-seasonal prediction. Nat. Clim. Chang. 2020, 10, 191-199. [CrossRef] 